\title{
Preparing Students for Leadership through Experiential Learning
}

\author{
Maria C. Bauermeister \\ Graduate Student \\ Seattle University \\ bauermei@seattleu.edu \\ Jon Greer \\ Graduate Student \\ Seattle University \\ greerj@seattleu.edu

\section{Angelina V. Kalinovich \\ Graduate Student \\ Seattle University \\ kalinovi@seattleu.edu}

\author{
Dr. Jennifer A. Marrone \\ Associate Professor, Management \\ Seattle University \\ marronej@seattleu.edu
}

Megan M. Pahl

Graduate Student

Seattle University

pahlm1@seattleu.edu

\section{Lauren B. Rochholz \\ Graduate Student \\ Seattle University \\ rochholz@seattleu.edu}

\section{Barry R. Wilson}

Graduate Student

Seattle University

wilsonb7@seattleu.edu

\begin{abstract}
This Application Brief highlights Seattle University's Red Winged Leadership (RWL) exercise, an innovative curriculum for graduate business leadership education. RWL requires students to apply course materials to a visible and challenging class project, and to critically examine and recognize leadership in the broader community. Both allow for development and execution of problem solving, critical thinking, and interpersonal skills necessary to lead successfully. Students are given an opportunity to develop self-awareness of their leadership
\end{abstract}


style, practice how to be an effective leader, use interpersonal skills to manage relationships, design a team structure, and execute a project. We recommend that instructors use the RWL as a template for graduate students to bridge the transition from learning leadership theories to applying them.

\section{Introduction}

Seattle University's Albers School of Business and Economics roots their education in Jesuit pedagogy, holistic education, and a focus on social justice. The Red Winged Leadership (RWL) exercise, offered to graduate students in the Master of Business Administration program's leadership formation courses, provides a unique chance for students to learn current leadership theory and an environment for them to apply it, giving them practical experience to transition from academics to practice. This paper will outline the structure of RWL as it is administered throughout two courses, Leadership Formation I and Leadership Formation II, and the respective course learning objectives. Finally, we will discuss outcomes, unique curriculum challenges, and recommendations for replication.

\section{Literature Review}

Leadership does not happen in a vacuum. According to Dugan and Komives (2010) "leadership is inherently a group phenomenon, and much of college is developmentally dedicated to a broadening sense of self in the context of others" (p. 539-540). Given that education on leadership is challenging but important, best environment consideration to educate future leaders is relevant. Eich (2008) found that higher education leadership programs provide opportunities for students to "engage with experienced and committed practitioners" who exemplifies leadership (p. 181).

Research also shows one of the most cited reasons for derailment in organizations is individuals being unprepared to take on leader responsibilities, despite being good at the technical job aspects (Caproni, 2005). Transitions need to be guided by preparing aspiring leaders for the future responsibility, which includes developing self-awareness (Avolio \& Hannah, 2008; Caproni, 2005). Additionally, aspiring leaders should be given the tools to identify and train others. Velsor and Drath (2004) note that the stage of leadership development particularly common to leaders in early career roles is the "self-reading" stage. In this stage, student's foundational beliefs about who they are and how they interact with the world are defined by what they read from other's feedback and responses.

While classroom and professional experiences are different, there is often crossoverof literature applicable to both settings. Available literature from the business realm, such as developing leadership in the workplace (Avolio \& Hannah, 2008; Kouzes \& Posner, 2006), authentic leadership (George, Sims, McLean, \& Mayer, 2007), servant leadership (Greenleaf, 1977), leader decision-making (Brousseau, Driver, Hourihan, \& Larsson, 2006; Garvin \& Roberto, 2001; Kim \& Maurborgne, 1997), and team leadership (Galbraith, Lawler III, \& O'Toole, 2002; Hackman, 2002) can enlighten students to ideas useful in both academic and workplace settings. According to U.S. News, over half of enrolled MBA students are continuing to work full-time; meaning the literature crossover is particularly useful (Hopkins, 2012). 


\section{Background and Description}

RWL is loosely modeled after the Opus Prize, "an annual faith-based humanitarian award, recognizing unsung heroes, who guided by faith and entrepreneurial spirit, are conquering the world's most persistent social problems" (The Opus Prize Foundation, 2014), which Seattle University co-hosted with the Opus Foundation in 2008. Inspired by the prize and when challenged by their professor to "identify, find and recognize leaders committed to the 'greater good' in the community," the inaugural group of students chose to look for inspiring and unsung individuals who integrated three essential pillars: leadership, business acumen, and positive social impact. With professor guidance, students crafted the "Red Winged Leadership" term, defined it as encompassing these three pillars, and created the brand and logo (Seattle University, 2014). The term references red-winged blackbirds whose unique red markings are initially hard to spot but once noticed, are hard to miss. Since the inception, five distinct cohorts, totaling eighty-seven students, have completed their own team-based exercise, centered on discerning their RWL definition and recognizing those who embody that definition.

RWL is completed over two courses, Leadership Formation I and Leadership Formation II. We move next to discussing particulars of each course to provide RWL details.

\section{Leadership Formation I}

Leadership Formation I began with challenging students' understanding of leadership through exploring theory and class activities meant to reframe thinking. Additionally, this course had the following primary deliverables: a leadership portfolio, defining the three RWL pillars, leader selection, assessment and presentation on someone believed to be a Red Winged Leader.

Desired learning outcomes of Leadership Formation I included: (a) clarifying students' ideas regarding the meaning and purpose of leadership; (b) students recognizing, differentiating, and critiquing major leadership styles and behaviors; (c) executing specific leadership skills; and (d) evaluating leaders in the community (Marrone, 2014a).

Toward those ends, students submitted a leadership portfolio early in the course where they defined leadership individually, and proposed quantifiable ways to measure leadership effectiveness. The portfolio activity prepared students to critically evaluate one's own leadership values. Additionally, leadership styles were explored in depth: visionary leadership (Kouzes \& Posner, 2006), authentic leadership (George, 2003), and servant leader (Greenleaf, 1977). These theoretical frameworks and the portfolios prepared students to define the three pillars of RWL and helped others to recognize leaders in the community and critically evaluate their styles according to each framework.

Again, each cohort revises the RWL definitions. Definitions created by the 2014-2015 cohort were: 
- Business Acumen - Red Winged Leaders demonstrate business acumen by being successful in their chosen industries and understanding organizational elements of finance, marketing, and communication;

- Leadership - leadership is empowering others to influence positive change for the community and inspiring others to go beyond their own expectations; and

- Social Impact - this person is inspired by the needs of their community as well as their own innate drive to create a positive, sustainable impact. (Marrone, 2014b)

Students identified community leaders from nonprofit and for-profit sectors, ranging from self-employment to executive management. After identifying and interviewing leaders, students evaluated them using a template, which includes questions about the leader's fulfillment of the RWL definition, their achievements, future plans, and leadership philosophy. The template was used to evaluate whether the leader met the Red Winged Leader criteria and to track student progress. Finally, it helps the professor assess student learning against learning objectives to see if students can identify, differentiate, and critique leadership styles and behaviors while evaluating their chosen leader. The processes of interacting with leaders and sharing the results with classmates allow students to learn about leadership theory, apply those theories with real-life examples of leadership, and to exercise the leadership skills of presenting, persuading, and communication.

\section{Leadership Formation II}

Leadership Formation II focused on selecting which leaders chosen from the previous course best exemplified RWL, while giving safe environment to practice leadership in a teambased context. The primary student deliverable for the class was finding a way to recognize the leaders. This project was broken into checkpoints: establish a team vision, form a team, refine vision and establish strategies, implement the vision, and present deliverable(s) (Marrone, 2015a). Students also completed reading and writing assignments relevant to the learning objectives.

Desired learning outcomes of Leadership Formation II included: (a) exploring various approaches to effectively leading people, relationships, teams; (b) developing self-awareness regarding individual preferences, motivators, characteristics; (c) developing, practicing, and executing problem solving, critical thinking and interpersonal skills necessary for success; and (d) a deliverable recognizing the selected Red Winged Leaders (Marrone, 2015a).

Toward those ends, students were responsible for designing and executing their plan by establishing teams and coordinating efforts. Cohorts have the power to be as innovative as desired in their leader recognition within the budget constraint of RWL. The freedom to selfdesign inherently created problem-solving opportunities and tested interpersonal skills as students executed their plan. Students had to establish team structure, vision, goals, and norms to create and implement their plan for selecting and recognizing the Red Winged Leaders. Past projects include hosting speaking events and creating video stories about the selected nominees. During this process, students often solicited external support to help with the completion of their projects. For example, in 2014, students were able to arrange a banquet to celebrate three leaders and present the RWL award to one of them. They contracted with local media, restaurants, and a 
videographer to execute the event and bring in approximately 225 attendees and substantial donations.

The process of working in a team to design and execute the deliverable offered a bridge between theoretical concepts explored in the readings, assignments and the application of leadership styles in a team setting. Assigned literature on leadership and behavior aligned to the project's milestones and guided students' leadership exploration. Useful theories include: shared leadership (Galbraith, et. al., 2002), decision-making styles (Brousseau, et. al., 2006; Gavin, et. al., 2001), and authentic leadership (George, et. al., 2007). These readings helped students develop self-awareness and critical thinking, which was useful when team conflicts arose and when members were experimenting with effectively leading people.

\section{Outcomes}

Notable and innovative student deliverables already described include creating a RWL brand as well as hosting public events, recognizing fifteen leaders to date. The RWL exercise has resulted in three primary outcomes arising from and supported by students' self-reported reflections on their learning and takeaways. The first evident outcome is a broader understanding of the range of effective leadership styles and abilities, including self-awareness of the students' personal leadership preferences. Second is valuable practice designing and leading teams that face similar challenges to those found in high-pressure work environments, generating additional insights about leadership in such contexts. A third outcome reported by students is enhancement of the students' preparedness to take on leader responsibilities in organizational settings. From course evaluations, students agree that the class structure and RWL have provided them a platform to practice and reflect on leadership theories that have been educational. The mean score across five years to date equaled 4.5 for the question "I would recommend this course" and 4.6 for the question "I learned a lot," both out of a five point scale (Marrone, 2015c). To elaborate further on the three outcomes outlined above, we draw from recent student quotes pulled directly from formal papers and reflections assignments during Leadership Formation I and II in 2014-2015. No student is quoted more than once.

First, in Leadership Formation I, the experience of reaching out to leaders added depth to class readings and discussions. Student reflections demonstrated an increased awareness and tangible insights gained about leadership. For example, the excerpt highlights the insights and perspective gained after interviewing his leader that isn't easily achieved in a typical classroom setting. This student, like many others, reports a broader understanding of the range of leadership styles and impacts of humility and social justice, connecting to several stated learning outcomes like clarifying ideas about leadership and recognizing leader styles and behaviors.

I'll never forget in my interview how I fed off her passion and was so caught up with her experiences... She inspired me to work towards working on the social impact and humility aspects of being a leader that I didn't previously feel were as important as leadership and business acumen in today's business world. 
Another student reported lessons learned in regards to her self-awareness:

One takeaway that I learned from [the leader] is it is important to not only identify the strengths you have at the table but to also identify what strengths are missing....First, you want to set people up for success and by giving them tasks that they feel comfortable in. Second, by recognizing from the start what strengths you're missing, you can go and find the resources you need in order to make your plan successful.

Second, in Leadership Formation II, a primary outcome is that students gained transferable practice and experience designing and leading teams facing realistic organizational challenges. Further, because of the self-designing nature of the team experience participants explored their personal leadership styles and team dynamic preferences organically and in a flexible setting. To quote a student's experience with the team:

[B] uilding a self-regulated team was a challenge when we're exploring leadership styles. It required reflection, communication, and a willingness to challenge each other and ourselves. Part of our success was due to our comfort with each other and another was the set of skills we learned about over this course, namely fair process, empowering peers and collective problem solving.

Another student accounted for the team's achievements as: "a result of the process, which started from identifying the norms. Many teams start with a clear objective, but very few take the time to establish the behavioral norms which guide the group's behavior." This and other students learned through hands-on experience that team structural elements, like setting norms, enable efficient decision-making. Further, when faced with time-sensitive deliverables, lack of consensus, and team friction, the strengths and weaknesses of different leadership approaches became apparent in a more palpable way.

Because of the openness of our class and team, I've been constantly reminded of the diversity of responses that people have different motivations and leadership styles. Additionally, maintaining a process that gives everyone a voice and makes decisions in a timely fashion is a challenge that seems even more apparent to me with shared leadership.

This reflection demonstrates links to stated learning outcomes, such as developing selfawareness regarding individual preferences, motivators, and characteristics. The student quotes illustrate how the classroom and practical experience combination has brought unique educational value to students.

Last, students report they're better prepared to be more effective leaders. This outcome for some students is highly sustainable, emerging one to two years after completion of RWL. At least three students to date attribute a career promotion to their outcomes achieved through this curriculum. Students take pride in highlighting their leadership development and accomplishments on their resumes and in interviews, which are then recognized and valued by employers. Each student's personal and professional outcomes vary based on their key takeaways about their own leadership style. As one example, a former student from the 2012 
cohort emailed the course professor in 2015 with the following reflection:

I wanted to reach out and THANK YOU for the foundation that you set for me in terms of developing people. I used a ton of Hackman and Authentic Leadership principles in my last role, which totally shifted my old work group's culture, and gave me the skills and credibility to land me in my current role. So - thanks! Truly. You gave me so much in that class and I still use it every day.

\section{Challenges and Recommendations}

Two sources of challenge associated with RWL are important to note for instructors: the use of self-designing teams and the varying stages of student leadership development. We discuss each and offer recommendations for specific supporting assignments that address these challenges.

First, the self-designing nature of RWL can bring a variety of uncertainties and frustrations alongside its opportunities for learning and development. Students are intentionally placed in situations where they have the responsibility for chartering new territory (e.g. setting direction for a real team, leading without explicit authority) and the felt experience of 'high stakes' while doing so (e.g. producing an end product that is often visible to the broader University and its external communities). Consequently, until leadership emerges many students experience the anxiety and chaos associated with 'leaderlessness.' This is also a time in which they try strategies among their peers that do not yield their desired results. This can force students to examine pre-existing beliefs and ideas about their leadership capabilities and influence. Finally, students often report feeling tension between performing daily tasks needed to accomplish team objectives with making the necessary time for reflection, learning, and development. It's easy to place primacy on 'getting the job done' rather than on underlying processes or learning.

Second, each student brings with them a different level of leadership development that has strong influences on her/his capacity to cope with challenges, complete assignments, and learn while doing so. It can be difficult to learn within classroom exercises that involve high discretion if the lack of clear directions and standards for performance is experienced as uncomfortable or threatening. Some students need clear direction and feedback from others to define who they are and how they relate, and may be unable to create their own sense of direction and structure. It's critically important to understand that these very same ill-structured experiences are necessary catalysts for moving individuals towards a new stage of development where they do develop the capacity to self-read and self-author to find their own direction and identity (Velsor \& Drath, 2004).

In response to these challenges, we recommend careful consideration be taken to design curriculum with intentional supporting assignments. Establishing supports is critical for learning to occur within developmental assignments (Ohlott, 2004) and is a contributing factor of team successes (Hackman, 1992). For instance, we first recommend that in Leadership Formation I, students be provided with a clear and explicit template to structure their data collection and interview efforts with the leaders. This helps to avoid unnecessary anxiety for students and 
enables consistency in the evaluation of the chosen leader's styles and impact. Second, establishing a few simple ground rules in Leadership II can help structure productive leadership emergence by providing students with a consistent reminder and 'push' toward inquiry modes (Garvin \& Roberto, 2001) and fair processes (Kim \& Maurborgne, 1997). For example, "Two Ground Rules" were presented in 2015. These were: "Any member who seeks to establish leadership influence or decision making authority must (a) clearly indicate their desire to do so to the team and (b) widely and effectively consult teammate opinions before making a decision" (Marrone, 2015b, p. 9). Ground rules served as a critical learning tool which pushed students to frequently solicit input from others, practice processing input in ways most beneficial to decision-making and least likely to result in information overload, and communicate a compelling decision back to their peers. Third, supporting reflection assignments are recommended throughout both courses. When not assigned, students routinely ask for such assignments. We suggest providing a flexible platform that allows students to pursue areas of interest in their reflections. Students can also be instructed to reflect as a team, using coaching guidelines provided by Hackman (1992).

We make five additional recommendations that apply broadly to this curriculum. First, accompanying literature should have an applied focus because it will set students up for success as they experientially work through the various aspects of defining leadership, identifying leaders, and recognizing leaders through a self-designed project. Through applied readings students will benefit by reflecting on how their classroom experiences relate to the work setting and vice versa. Second, class size should influence team structures and deliverables. For example, a small class might decide to work as one team and have a deliverable different from a larger class working in multiple teams. As such, accompanying readings should be adjusted to complement the challenges different class structures bring and the students' emerging questions. Third, both students and faculty should recognize that RWL requires a high level of student ownership for successful completion, which can be a time-consuming process. Students can decide if they want to gain external support to aid in completion; past cohorts found this to be effective. Fourth, significant time during class sessions should be given for teams to engage in reflection and teamwork. This provides an opportunity to observe the team directly, significantly aiding the professor in her/his ability to discern when intervention in team processes is likely to be beneficial and when not. Finally, the stages of leadership development and/or leadership readiness (Avolio \& Hannah, 2008) should be routinely discussed with the intention of promoting the awareness and empathy needed by all for students to manage and grow from challenges.

\section{Conclusion}

In conclusion, RWL strives to prepare students to succeed as they enter leadership roles through an innovative experiential process. Tasks such as identifying and interviewing Red Winged Leaders, designing a team, and executing a team project were central to the innovative nature of RWL. The experiential process allows students the opportunity to apply concepts and learn further about the challenges of transitioning from theory to application. Class discussions and consistent self-reflection added depth to the learning by requiring students to support and challenge their own and others' assumptions regarding leadership. With our recommendations in mind, a curriculum that reflects RWL will provide a unique chance for graduate students to learn 
current leadership theory and a safe environment for them to apply it; giving them practical experience to help bridge the transition from academics to practice.

\section{References}

Avolio, B., \& Hannah, S. (2008). Developmental readiness: Accelerating leader development. Consulting Psychology Journal: Practice and Research, 60(4), 331-347. doi: 10.1037/1065-9293.60.4.331

Brousseau, K. R., Driver, M. J., Hourihan, G., \& Larsson, R. (2006). The seasoned executive's decision-making style. Harvard Business Review, 84(2), 110-121.

Caproni, P. (2005). Management skills for everyday life: The practical coach. Upper Saddle River, NJ: Pearson Prentice Hall.

Dugan, J. P., \& Komives, S. R. (2010). Influences on college students' capacities for socially responsible leadership. Journal of College Student Development, 51, 525- 549. doi: 10.1353/csd.2010.009

Eich, D. (2008). A grounded theory of high-quality leadership programs: Perspectives from student leadership development programs in higher education. Leadership \& Organization Studies, 15(2), 176-187. doi: 10.1177/1548051808324099

Galbraith, J., Lawler III, E. E., \& O’Toole, J. (2002). When two (or more) heads are better than one: The promise and pitfalls of shared leadership. California Management Review, 44(4), 65-83.

Garvin, D. A., \& Roberto, M. A., (2001). What you don't know about making decisions. Harvard Business Review, 79(8), 108-116.

George, B., Sims, P., McLean, A. N., \& Mayer, D. (2007). Discovering your authentic leadership. Harvard Business Review, 85(2), 129-138.

Greenleaf, R. (1977). Servant leadership: A journey into the nature of legitimate power and greatness. New York, NY: Paulist Press.

Hackman, J. (2002). Leading teams: Setting the stage for great performances. Boston, MA: Harvard Business School Press.

Hopkins, K. (2012, March 14). Weigh costs of part-time and full-time MBA programs. US News \& World Report. Retrieved May 12, 2015, from http://www.usnews.com/education/bestgraduate-schools/paying/articles/2012/03/14/weigh-costs-of-part-time-and-full-time-mbaprograms

Kim, W. Chan, \& Maurborgne, R. (1997). Fair process: Managing in the knowledge economy. Harvard Business Review, 75(4), 65-75. 
Kouzes, J., \& Posner, B. (2006). A leader's legacy. San Francisco, CA: Jossey-Bass.

Marrone, J. (2014a). Leadership Formation I course syllabus and assignments. [Class handout]. Department of Management, Seattle University, Seattle, WA.

Marrone, J. (2014b). Red Winged Leadership definitions. [Class presentation]. Department of Management, Seattle University, Seattle, WA.

Marrone, J. (2015a). Leadership Formation II course syllabus and assignments. [Class handout]. Department of Management, Seattle University, Seattle, WA.

Marrone, J. (2015b). Team composition report [Class handout]. Department of Management, Seattle University, Seattle, WA.

Marrone, J. (2015c). Leadership Formation I and II course evaluation results. [Class presentation]. Department of Management, Seattle University, Seattle, WA.

Ohlott, P. J. (2004). Job assignments. In C. D. McCauley \& E. V. Velsor (Eds.), The Center for Creative Leadership: The handbook of leadership development ( $2^{\text {nd }}$ ed., pp. 151-182). San Francisco, CA: John Wiley and Sons.

Seattle University. (2014). Graduate leadership formation specialization. Retrieved May 12, 2015 from https://www.seattleu.edu/albers/graduate/certificates/leadership/glfs/.

The Opus Prize Foundation. (2014). Overview of the Prize. Retrieved May 12, 2015 from http://www.opusprize.org/about/overview.cfm.

Van Velsor, E. \& Drath, W. H. (2004). A lifelong developmental perspective onleader development. In C. D. McCauley \& E. V. Velsor (Eds.), The Center for Creative Leadership: The handbook of leadership development ( $2^{\text {nd }}$ ed., pp. 383-414). San Francisco, CA: John Wiley and Sons.

\section{Author Biographies}

Maria C. Bauermeister is currently a graduate student in the Professional Master of Business Administration program at the Albers School of Business and Economics, Seattle University. She received her undergraduate degree in Business from Alaska Pacific University. Maria's current research interests are in the application of neuroscience to business.

Jon Greer (greerj@seattleu.edu) is currently a graduate student in the Professional Master of Business Administration program at the Albers School of Business and Economics, Seattle University.

Angelina V. Kalinovich is currently a graduate student in the Professional Master of Business Administration program at the Albers School of Business and Economics, Seattle 
University. Her areas of focus are Leadership Formation and Business Analytics. She received her Bachelor degree in International Studies and Spanish from Seattle University.

Megan M. Pahl (pahlm1@ seattleu.edu) is currently a graduate student in the Professional Master of Business Administration program at the Albers School of Business and Economics, Seattle University. She received her undergraduate degree in English and Communication from the College of Saint Benedict. Megan works at The Incredible Years as the Director of Operations.

Lauren B. Rochholz (rochholz@ seattleu.edu) is currently a graduate student in the Professional Master of Business Administration program at the Albers School of Business and Economics, Seattle University. She received her Master of Sport Administration and Leadership from Seattle University and her Bachelor of Arts in Economics and Religious Studies from Gonzaga University.

Barry R. Wilson is currently a graduate student in the Professional Master of Business Administration program at the Albers School of Business and Economics, Seattle University.

Jennifer A. Marrone (marronej@ seattleu.edu) is an associate professor of management at the Albers School of Business and Economics, Seattle University. She received her Ph.D. from the Robert H. Smith School of Business, the University of Maryland, College Park. Her current research interests focus on team processes, performance, and leadership, with an emphasis on applying multilevel perspectives and techniques. 